\title{
Prediction of Sludge Reduction of Polymerized-organic-Al-Zn-Fe (POAZF) Coagulant
}

\author{
Ying Fu, Yanzheng Wang \\ School of Civil Engineering and Architecture, University of Jinan, Shandong, 250022 China
}

\begin{abstract}
A new coagulant of polymerized-organic-Al-Zn-Fe (POAZF) was prepared using a galvanized aluminum slag and polyacrylamide (PAM) as raw materials. Sludge reduction of POAZF was probed compared to that of poly-Al-Zn-Fe (PAZF) and poly-aluminum-chloride (PAC). The results showed that the settling speed of flocs of POAZF was much greater than that both PAZF and PAC. The volume reduction ratio of wet sludge (VRRWS) of POAZF was fitted in polynomial mode to predict VRRWS. The fitting precision of VRRWS achieved by POAZF between the test data and fitting data at both higher dosage and lower or medium dosage within the settling time of 15 min was high, which is significant for sludge production and VRRWS in the actual wastewater treatment processes.
\end{abstract}

Keywords-Fe-Zn-Al; PAM; sludge reduction; prediction.

\section{INTRODUCTION}

For many years, sludge treatment has not been received enough attention in China, and until currently, only about $25 \%$ sludge has been disposed in harmless methods [1]. Even some cities appeared to be surrounded by sludge, so bringing about serious risks to the environment.

Sludge reduction is a new concept put forward in the 1990 s [2-5]. Recently, many studies on biological sludge reduction technologies have been extensively performed [69]. However, reports on how to reduce chemical sludge has been rarely published. So the studies on reducing chemical sludge still has great significance in developing countries, in which high efficiency coagulants are still more and more important in the field of sludge reduction.

In addition, China has become one of the most polluted countries caused by solid wastes due to its rapid economy development. Therefore, the disposal of solid wastes becomes more and more important, and resource utilization becomes one of the main treatment methods, in which the preparation of inorganic and organic coagulants with various solid wastes is still a hot topic in the field of water treatment [10-12].

In this paper, POAZF coagulant was made using a galvanized-aluminum slag and PAM as main materials. And the sludge reduction and its prediction were then studied.

\section{MATERIALS AND METHODS}

\section{A. Preparation of POAZF.}

PAM solution (1\% $(w / w)$, analytical grade) was added into a color-free filtrate prepared in the previous report [11] with stirring to obtain a solution. After stirring $5 \mathrm{~min}$, $\mathrm{NaOH}$ solution (5\% $(w / w)$, analytical grade) was added slowly into the solution at $30-70{ }^{\circ} \mathrm{C}$ and stirring to obtain a mixed solution with $\mathrm{pH}$ of 2.0-3.0 (PB-10 $\mathrm{pH}$ meter, Germany), and was then followed by 5-72 h of polymerization to obtain a light-brown liquid of POAZF with $w(\mathrm{Al})$ of $2.43 \%, w(\mathrm{Zn})$ of $1.15 \%, w(\mathrm{Fe})$ of $0.26 \%$, and density of $1.09 \mathrm{~kg} / \mathrm{L}$.

The preparation of PAZF was published in the previous report [11] and solid PAC $\left(w\left(\mathrm{Al}_{2} \mathrm{O}_{3}\right)=29 \%\right)$ was purchased from Jinan in China.

\section{B. Jar test.}

The tested water sample was taken from campus of University of Jinan. The qualities of the tested water were as follows: Turbidity $=159$ NTU, $\mathrm{pH}=7.4-7.69$, Temperature $=17-21^{\circ} \mathrm{C}, \mathrm{COD}_{\mathrm{Cr}}=386 \mathrm{mg} / \mathrm{L}$.

POAZF, PAZF and PAC were used as coagulants in the following experiments, and the dosage varied between 62 and $372 \mathrm{mg} / \mathrm{L}$ (as aluminum amount in water samples).

Coagulant was added rapidly into the water samples (1 L) which were in the cups on a six-unit multiple stirrer system (ZR4-6 flocculator, zhongrun, China). A rapid mixing stage was conducted at $200 \mathrm{r} / \mathrm{min}$ for $1 \mathrm{~min}$, and then followed by a slow mixing stage of $10 \mathrm{~min}$ at $50 \mathrm{r} / \mathrm{min}$ to form the flocs. The flocs was then settled for different times for the following tests.

\section{Settling performance of flocs and prediction of sludge reduction.}

Wet sludge refers to the sum of the flocs containing water. The flocs after flocculation $10 \mathrm{~min}$ (in Section 2.2) by coagulants was introduced into $100 \mathrm{ml}$ measuring cylinder. And the changes of the settling performance of flocs at dosages of 62, 186 and $372 \mathrm{mg} / \mathrm{L}$ and settling time of 5-30 min were observed. The volume change of wet sludge was analyzed.

\section{RESULTS AND DISCUSSION}

\section{A. Settling performance of flocs.}

As indicated in Fig.1, settling performance of flocs of POAZF was much superior to that of PAZF and PAC at the given dosages.

The flocs of POAZF almost settled completely at 15, 25 and $20 \mathrm{~min}$ at dosages of 62 (Fig.1a), 186 (Fig.1b) and 372 $\mathrm{mg} / \mathrm{L}$ (Fig.1c), respectively, compared to that of PAZF and 
PAC at 25, 25 and $30 \mathrm{~min}$, and at 25, 30 and $30 \mathrm{~min}$, respectively. So the complete settling times of POAZF at dosage of 62, 186 and $372 \mathrm{mg} / \mathrm{L}$ were $40 \%, 0 \%$ and $33.3 \%$ shorter than that of PAZF, and $40 \%, 16.7 \%$ and $33.3 \%$ shorter than that of PAC, respectively. The volume of wet sludge after complete settlement at dosage of 62, 186 and $372 \mathrm{mg} / \mathrm{L}$ was that POAZF was 8, 21 and $11 \mathrm{~mL}, \mathrm{PAZF}$ was 12,32 and $15 \mathrm{~mL}$, and PAC was 14,32 and $30 \mathrm{~mL}$. That is, the volume reduction of wet sludge of POAZF at dosages of 62,186 and $372 \mathrm{mg} / \mathrm{L}$ were $33.3 \%, 34.4 \%$ and $26.7 \%$ (as volume reduction ratio of wet sludge (VRRWS)) less than that of PAZF, and $42.8 \%, 34.4 \%$ and $63.3 \%$ less than that of PAC.
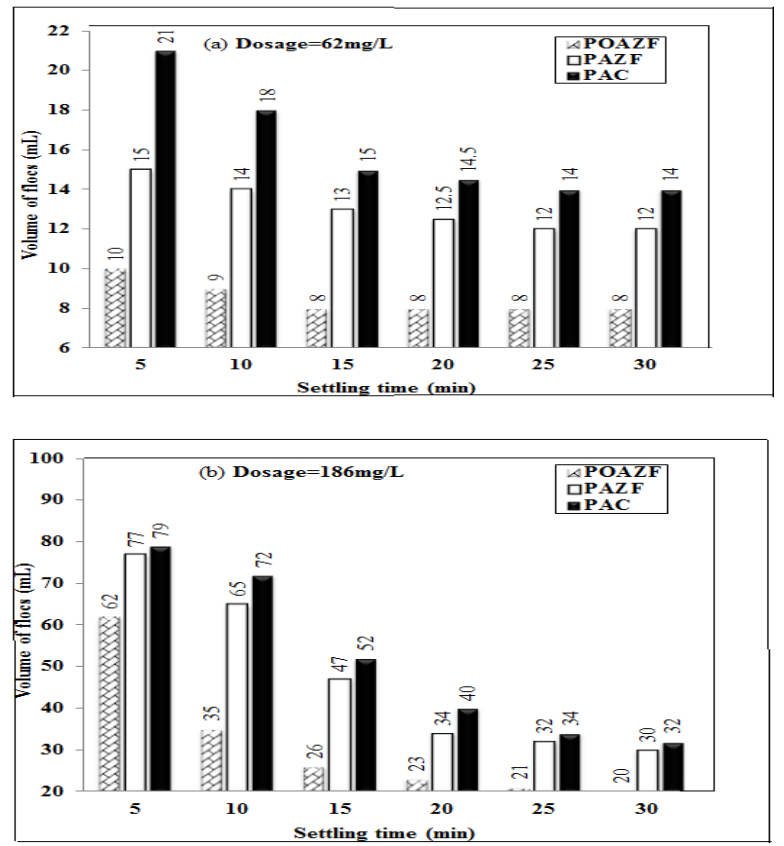

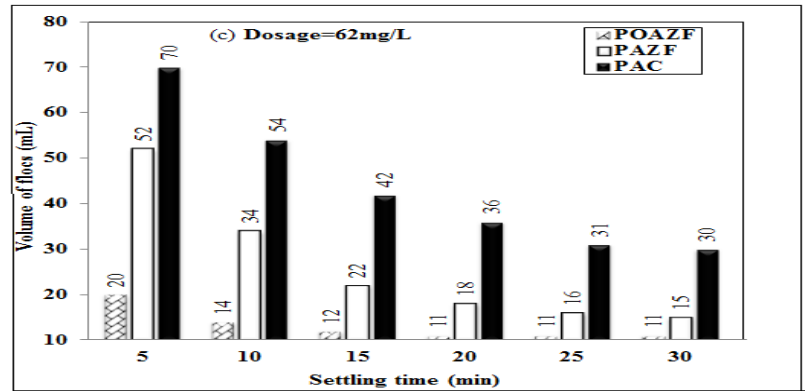

Figure 1. Influence of settling time and dosage of on settling performance of POAZF, PAZF and PAC

As also shown in Fig.1, within the settling times, the VRRWS of POAZF was from 33.3-38.5\% (62 mg/L), 19.5$46.2 \%(186 \mathrm{mg} / \mathrm{L})$ and $26.7-61.5 \%(372 \mathrm{mg} / \mathrm{L})$ compared to that of PAZF, and 42.9-52.4\% (62 mg/L), 21.5-51.4\% (186 $\mathrm{mg} / \mathrm{L}$ ) and $63.3-74.1 \%$ (372 $\mathrm{mg} / \mathrm{L})$ compared to that of PAC, respectively.

\section{B. Prediction of sludge reduction.}

To predict VRRWS of POAZF at different settling times and different dosages, settling curve of flocs of POAZF was fitted in polynomial mode according to its tested data, compared to that of PAZF and PAC, as shown in Table 1.

As seen in Table 1 , the range of $\mathrm{R}^{2}$ was from 0.9889 to 1 , suggesting that the polynomial fitting curve had good reliability. The change of VRRWS of POAZF with dosage at different settling times (0-35 min) was calculated according to the polynomial fitting curve displayed in Table 1, compared with that of PAZF or PAC, respectively, and then compared with the real tested data at settling times from $5 \mathrm{~min}$ to $30 \mathrm{~min}$. The results were graphed in Fig.2.

TABle I. Polynomial Fitting Curve Of Flocs Settlement

\begin{tabular}{|c|c|c|c|c|}
\hline \multicolumn{2}{|c|}{$\begin{array}{l}\text { Coagulant } \\
\text { Dosage }(\mathrm{mg} / \mathrm{L})\end{array}$} & 62 & 186 & 372 \\
\hline \multirow[t]{2}{*}{ POAZF } & Polynomial trend line & $\begin{array}{l}y=-4 E-05 x^{4}+0.0028 x^{3}-0.054 x^{2} \\
+0.2028 x+10\end{array}$ & $\begin{array}{l}y=0.0004 x^{4}-0.0354 x^{3}+ \\
1.1689 x^{2}-17.478 x+124.33\end{array}$ & $\begin{array}{l}y=-0.0015 x^{3}+0.1049 x^{2}- \\
2.4384 x+29.667\end{array}$ \\
\hline & $\mathrm{R}^{2}$ value & 0.9889 & 1 & 0.9967 \\
\hline \multirow[t]{2}{*}{ PAZF } & Polynomial trend line & $\begin{array}{l}y=-2 E-05 x^{4}+0.0016 x^{3}-0.0374 x^{2} \\
+0.1378 x+15\end{array}$ & $\begin{array}{l}y=-0.0007 x^{4}+0.0549 x^{3}- \\
1.3283 x^{2}+9.3516 x+57\end{array}$ & $\begin{array}{l}y=-0.0032 x^{3}+0.2565 x^{2}- \\
7.0378 x+81.333\end{array}$ \\
\hline & $\mathrm{R}^{2}$ value & 0.9953 & 0.9997 & 0.999 \\
\hline \multirow[t]{2}{*}{ PAC } & Polynomial trend line & $\begin{array}{l}y=-0.0001 x^{4}+0.0072 x^{3}- \\
0.1454 x^{2}+0.5434 x+21\end{array}$ & $\begin{array}{l}y=0.0059 x^{3}-0.2494 x^{2}+ \\
0.5497 x+82.667\end{array}$ & $\begin{array}{l}y=3 E-05 x^{4}-0.0034 x^{3}+0.1875 x^{2} \\
-5.5437 x+93.5\end{array}$ \\
\hline & $\mathrm{R}^{2}$ value & 0.9921 & 0.9895 & 0.9993 \\
\hline
\end{tabular}

based on fitting curve and tested data, and the greater the $\mathrm{R}^{2}$, the reliability of the fitting curve. 

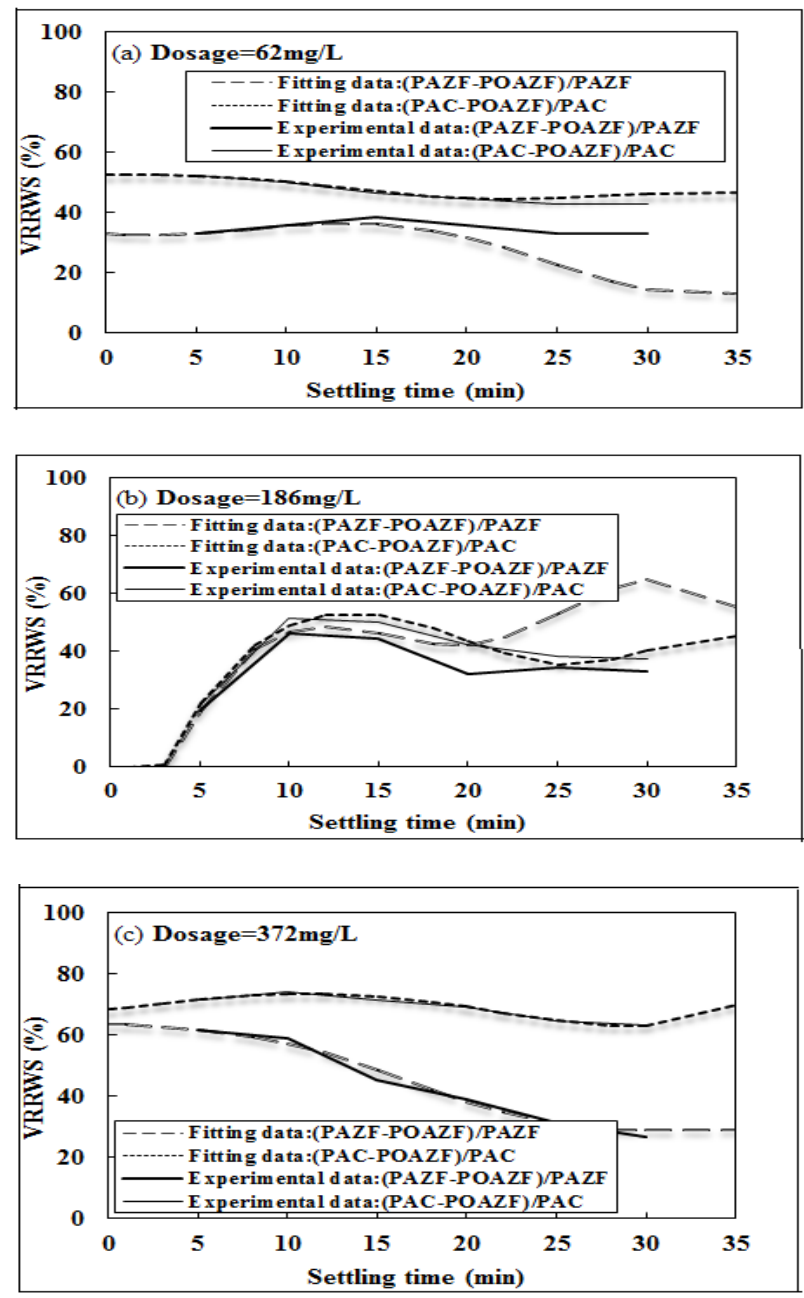

Figure 2. Comparison of VRRWS of POAZF between tested and caluating data at defferent dasages and settling time (compared to PAZF and PAC).

As seen in Fig.2, the fitting precision of VRRWS posed by POAZF between the tested and fitting data was greater than that by PAZF at high dosage $372 \mathrm{mg} / \mathrm{L}$, with the error range of POAZF from $0.47 \%-8.05 \%$. While at lower or medium dosage, the fitting precision of VRRWS posed by POAZF was high within the settling time of $15 \mathrm{~min}$, and followed by a drastic decrease, down to $56.95 \%$ at dosage of $186 \mathrm{mg} / \mathrm{L}$ and $94.38 \%$ at dosage of $372 \mathrm{mg} / \mathrm{L}$, respectively. So the fitting precision of VRRWS achieved by POAZF will be good within $5 \mathrm{~min}$. Therefore, the VRRWS of POAZF within $15 \mathrm{~min}$ can be basically predicted according to the polynomial fitting curves in Table 1, which is of significance for the production rate and VRRWS during the actual waste water treatment processes.

The fitting precision of VRRWS of PAZF between the tested and fitting data was higher than that of PAC, with the error range of PAZF from $0.15 \%-7.69 \%, 2.9 \%-8.2 \%$, and $0 \%-0.88 \%$ at dosage of 62, 186 and $372 \mathrm{mg} / \mathrm{L}$, respectively.

\section{CONCLUSIONS}

The settling time of POAZF at dosage of 62, 186 and $372 \mathrm{mg} / \mathrm{L}$ was $40 \%, 0 \%$ and $33.3 \%$ shorter than that of PAZF, and $40 \%, 16.7 \%$ and $33.3 \%$ shorter than that of PAC, respectively. Volume of sludge POAZF reduced from $19.5 \%$ to $61.5 \%$, and $21.5 \%$ to $74.1 \%$ compared to that of PAZF and PAC at different dosages, respectively.

The volume reduction ratio of wet sludge (VRRWS) of POAZF was fitted in polynomial mode to predict VRRWS. Compared to PAZF, the fitting precision of VRRWS of POAZF was higher at high dosage $(372 \mathrm{mg} / \mathrm{L})$, and within settling time of $15 \mathrm{~min}$ at lower or medium dosage.

\section{V.ACKNOWLEDGEMENTS}

This research was supported by a financial from Shandong Outstanding Young Scientist Award Foundation Funded Project and (SBS1112).

\section{REFERENCES}

[1] Xu, Q., New technologies, new processes and new equipment in sludge treatment and disposal. Beijing: Chemical Industry Press, pp. 45-47, 2011.

[2] Campos, J.L., Otero, L., Franco, A., Mosquera-Corral, A. \& Roca, E., Ozonation strategies to reduce sludge production of a seafood industry WWTP. Bioresour. Techno., 100, pp. 1069-1073, 2009.

[3] Egemen, E., Corpening, J., \& Nirmalakhandan, N., Evaluation of an ozonation system for reduced waste sludge generation. Water Sci. Technol., 44, pp. 445-452, 2001.

[4] Zhang, G.M., He, J.G., Zhang, P.Y. \& Zhang, J., Ultrasonic reduction of excess sludge from activated sludge system: Urban sewage treatment. J. Hazard. Mater., 164, pp. 1105-1109, 2009.

[5] Wu, Y.W., Study on sludge reduction and growth characteristics of function microbe, dissertation for master degree in engineering. Harbin Institute of Technology, 2013.

[6] Camacho, P., Ginestet, P. \& Audic, J.M., Understanding the mechanism of thermal disintegration treatment in the reduction of sludge production. Water Sci. Technol., 52, pp. 235-245, 2005.

[7] Foladori, P., Andreottola, G. \& Ziglio, G., Sludge reduction technologies in wastewater treatment plants. IWA Publishing, London, 2010.

[8] Tamis, J., Van Schouwenburg, G.V., Kleerebezem, R. \& Van Loosdrech, M.C.M., A full scale worm reactor for efficient sludge reduction by predation in a wastewater treatment plant. Water Res., 45, pp. 5916-5924, 2011.

[9] Wang, Q.L., Ye, L., Jiang, G.J. \& Yuan, Z.G., A free nitrous acid (FNA)-based technology for reducing sludge production. Water Res., 47, pp. 3663-3672, 2013.

[10] Szabó, E., Vajda, K., Veréb, G., Dombi, A., Mogyorósi, K., Ábrahám, I. \& Májer, M., Removal of organic pollutants in model water and thermal wastewater using clay minerals. J. Environ. Sci. Heal. A, 46, pp. 1346-1356, 2011.

[11] Fu, Y., Zhang, J.C., Wang, Y.Z. \& Yu, Y.Z., Resource preparation of poly-Al-Zn-Fe (PAZF) coagulant from galvanized aluminum slag: characteristics, simultaneous removal efficiency and mechanism of nitrogen and organic matters. Chem. Eng. J., 203, pp.3 01-308, 2012.

[12] Piazza, G.J., McAloon, A.J. \& Garcia, R.A., A renewable flocculant from a poultry slaughterhouse waste and preliminary estimate of production costs, resources. Conservation and Recycling, 55, pp. 842-848, 2011. 